\title{
Comunicación y Medios: 2000
}

Por Sergio Contardo Egaña

\author{
Nacimiento
}

Hace casi veinte años apareció el número $1^{\circ}$ de la Revista "Comunicación y Medios". Nacía del seno de la Escuela de Periodismo de la Universidad de Chile, dentro del Departamento de Ciencias y Técnicas de la Comunicación y, para mayor detalle, al interior de la Facultad de Filosofía y Educación.

Fue dirigida y escrita por profesores de dicha Escuela, y editada e impresa en sus propios talleres gráficos por funcionarios de ella. Algunas de esas personas han fallecido, otras han jubilado o han partido a diferentes hogares y un número pequeño aún continúa laborando en esta unidad académica. Cuando nació, los talleres que la dieron a luz funcionaban en un edificio construido especialmente para la Escuela, en la calle Los Aromos, junto al Decanato de la Facultad de Filosofía y Educación y al antiguo Pedagógico. Los avatarres políticos obligaron al traslado de la Escuela hacia una pequeña e inapropiada torre, en cuyos pisos bajos hubo que arrimar las partes del taller que pudieron resistir la mudanza. Allí se siguió trabajando en la revista, pasando por las inclemencias de paros, bombas lacrimógenas, protestas, intromisiones policiales y otras actividades académicas semejantes.

Más tarde, una segunda mudanza a la calle Belgrado, hoy Periodista José Carrasco, continuó destruyendo los implementos de la imprenta pero, crujiendo y rechinando, la revista "Comunicación y Medios" logró llegar a su número 11. Lo hizo con la frente limpia pero cansada y casi olvidada. Los cambios políticos, junto con la democracia y la libertad, trajeron convulsiones y anarquías, muchos directores de la Escuela de periodos breves, tensos y difíciles, tomas, renuncias y cambios a veces paralizantes.

Hoy, normalizada en gran parte la actividad académica en el ahora denominado Departamento de Investigaciones Mediáticas y de la Comunicación y en su Escuela de Periodismo, la revista vuelve a la vida, con otras caras, otras energías e ilusiones, iniciando así su segundo periodo. Los que participamos del primero, desde el silencio y el recogimiento de nuestros escritorios, manteniendo la fe en la grandeza del trabajo universitario, que volvemos a ver en quienes con entusiasmo reemprenden la labor, esperamos que contra el dicho clásico la segunda parte no sólo sea buena, sino mejor que la primera.

\section{Números}

La Escuela de Periodismo de la Universidad de Chile nació el año 1953, vale decir hace 47 años. En 1980, cuando cumplió 28 años, y luego de 7 años de gobierno militar, preparó y editó su primera revista: "Comunicación y Medios", la que por razones técnicas sólo apareció en 1981. El tiempo va pasando con velocidad apresurada. Al celebrar la Escuela sus 40 años de vida, un número doble de la revista se sumó al feliz aniversario que en su celebración incluyó salón de honor, discurso rectorial y directorial y, por supuesto, editorial recordatorio. El gran esfuerzo agotó muchas energías. El aire de la democracia y de la libertad envolvía las aulas y las oficinas, junto con ello los dineros para publicaciones se acabaron y la revista, calladamente, preparó su último número. Tras la paletada, nadie dijo nada.....

Pero las nuevas energías acortaron los plazos. Siete años demoró en reaparecer la revista, es decir la cuarta parte del tiempo que requirió su primer nacimiento. Los números son importantes y misteriosos. Entre la fundación de la Escuela y la aparición de "Comunicación y medios" aquella tuvo 7 directores. La revista se calló en 1993, hace 7 años. En el curso de esos 7 años la Escuela de Periodismo tuvo también 7 directores. Los 7 primeros números de la revista aparecieron puntualmente año tras año, al cabo de los cuales hubo que recurrir a los números dobles. 


\section{Entorno}

La Escuela de Periodismo de la Universidad de Chile nació con la ayuda de famosas personalidades: Juvenal Hernández, Juan Gómez Millas, Santiago del Campo, Ernesto Montenegro, Mario Ciudad, Ramón Cortés Ponce, Juan Emilio Pacull. El presidente de la República, Carlos Ibáñez, abrió la billetera fiscal y entregó \$4.000.000. - para su creación y funcionamiento. La Universidad facilitó su primer hogar. Luego una hermosa venezolana, cuya atrayente y distinguida imagen nos acompaña colgada en la pared de la sala de reuniones, donó \$ 16.000.000.- para construir un local especial a la nueva creatura universitaria. Curiosamente el edificio lo levantó la Sociedad Constructora de establecimientos Educacionales, a la que el Ministerio de Educación pagaba un arriendo para que lo ocupara la Escuela de Periodismo. Se contaba por testigos ya desaparecidos que la constancia documentada de este hecho misterioso no quedó en los archivos de una Notaría o de un Conservador de Bienes Raíces, sino que, de acuerdo con el poético destino de la Escuela, se enterró bajo sus cimientos. En ese local se gestó "Comunicación y Medios".

Eran tiempos bravos. Las diferencias ideológicas, sanas manifestaciones de la libertad democrática, se habían transformado en fuertes pugnas y al compás de las convulsiones de la política nacional, también surgieron en la Universidad sedes opuesta y escuelas paralelas. Periodismo no fue una excepción y las opiniones políticas empezaron a superar arrolladoramente a los esfuerzos académicos. La milicia entró en escena y con un mandoble renovó el corte gordiano de Alejandro. La Escuela tembló y muchos desaparecieron de sus cátedras y de sus aulas. Los sobrevivientes trataron de curar las heridas. A esa labor nos sumamos algunos que sufrimos el vendaval en otras casas universitarias.

Fue una especie de segundo nacimiento. Hubo que recuperar semestres perdidos; rehacer trabajosa y pacientemente el historial académico de los alumnos; completar con dificultades los cuadros docentes; normalizar planes de estudios aplicados de hecho sin reconocimiento de derecho; recuperar el sentido de la carrera; ordenar o reelaborar sus programas; convalidar ramos desaparecidos con otros recién nacidos; preparar un nuevo currículum considerando los avances de las ciencias de la comunicación y la forma en que países más avanzados resolvían estos problemas.Todo ello con magros presupuestos, con mucha seriedad pero también con mucha calma para no despertar reacciones negativas en años de estado de sitio, toque de queda y bandos militares. Pero los resultados compensaban los esfuerzos. Entre aquellos recordamos con especial afecto la aparición de "Comunicación y Medios".

\section{Contenidos}

La revista surgió como una necesidad. La enseñanza del Periodismo resultaba difícil en momentos tensos como los que se vivían, pero al mismo tiempo aparecía como una misión indispensable. Era necesario contribuir a crear un clima en el que la libertad de expresión se hiciera una realidad para que contribuyera a la obtención, al menos paulatina, de una convivencia verdaderamente democrática. Por ello la temática desarrollada en la revista se orientaba a estudiar y analizar aspectos científicos y técnicos de la Comunicación Social en los nuevos tiempos.

Al revisar los números publicados se puede notar como esta preocupación está presente en todos ellos, en variadas formas, a través de serias y útiles colaboraciones. Podemos también observar que los problemas profesionales -en una época en que los increíbles progresos tecnológicos influyen en las más diversas formas en el desarrollo de la función periodísticason tratados desde diversos puntos de vista, con la clara intensión de que su desarrollo y progreso estén presentes, tanto en su conocimiento teórico como en su aplicación práctica a las labores docentes.

$\mathrm{Y}$ en tercer lugar desde su número inicial se advierte con mucha claridad el interés permanente por el tema de la libertad de expresión. Ella es enfocada en su configuración constitucional, en los momentos en que un plebiscito aprobaba la nueva constitución de la República de Chile. Se analizó variadamente el desarrollo de la legislación sobre prensa 
existente en nuestro país desde su nacimiento como República hasta la aprobación de la nueva carta fundamental, en años en que aquel valor sufría merma y deterioro.

En este movimiento de lenta recuperación de la libertad de expresión, la revista dio cuenta de la permanente y activa presencia de la Escuela tanto en la reacción en contra de una legislación aberrante dictada en 1984, como en la elaboración del proyecto de nueva ley sobre libertad de opinión e información y ejercicio del periodismo, que contemplaba un horizonte de respeto e independencia para la profesión periodística y cuya discusión, después de tantos años, aún está pendiente en el Parlamento.

\section{Nombres}

Cuando nació "Comunicación y Medios" la Escuela de Periodismo se denominaba "Departamento de Ciencias y Técnicas de la Comunicación", lo que obedeció a la nueva estructura departamentalizada de la Universidad. El entonces director de ella, Eduardo Latorre, fue un impulsor de la revista y uno de sus constantes colaboradores. El primer director fue un joven profesor de la Escuela que antes de la intervención de la milicia había ejercido las funciones de Coordinador de Estudios: Raúl Muñoz. (Ahora, después de una intensa experiencia docente y simbolizando la continuidad del espíritu de la Escuela de Periodismo, vuelve a desempeñar en ella las labores de Jefe de Carrera y a participar activamente en este nuevo nacimiento). A partir del número 2 de la revista ocupó el cargo de director de ella quien escribe estas líneas. Y aprovechando esta mención conviene recordar algunos nombres que en aquellos turbulentos años nos ayudaron a cumplir simultáneamente las delicadas y variadas actividades de Docente, Coordinador de Estudios, Subdirector del Departamento y de la Escuela y Director de "Comunicación y Medios".

En los números de la revista escribieron egresados y titulados en la Escuela de Periodismo de la Universidad de Chile. Excusando el posible olvido de algunos nombres recordamos a Luis Ochoa -perteneciente al curso fundador de la Escuela en 1953-, Willy Wolf, quien además era el encargado de la imprenta, Werner Arias, Abrahan Santibáñez, María Eugenia Oyarzún, Raúl Muñoz, Guillermo Castillo, Barbara Délano, Maribel Quezada, Alberto Luengo, Alexis Vásquez, Myriam Orellana; también queremos recordar a otros profesores que colaboraron en la revista con sus valiosos aportes, como Alfredo Valdés, Edmundo Concha, Sergio Prenafeta, Paz Larraín, Ilse Sasso, Oscar Aguilera, Jorge Acevedo, María Eugenia Fontecilla.

Junto a los nombres recordados no pueden olvidarse los de aquellos que aunque no escribieron en la revista, encarnaron el espíritu que dio tanto vida académica y profesional como continuidad a la Escuela: Gonzalo Beltrán, Sergio Carrasco, Luis Fernández Navas, Mauricio Amster, Domingo Ulloa, Walter Fernández, Nicolás Luco, Luis Cruz, Samuel Mena, Gonzalo Becerra y el inolvidable mayordomo de la Escuela, cuya imagen representa al valioso grupo del personal administrativo y auxiliar: don Alfredo García.

\section{Doctrina}

La revista "Comunicación y Medios" a lo largo de sus años de vida y a través de la exposición del variado pensamiento de sus colaboradores, desarrolló una clara posición acerca de la esencia y del sentido del Periodismo. Siempre afirmó que, en la actualidad, éste no era una mera técnica sino que constituía una profesión, tal como lo son la medicina, la abogacía, la pedagogía y todas las otras actividades análogas que la ley, previa la correspondiente titulación universitaria, reconoce expresamente como tales. Diversos artículos presentaron y defendieron esta posición que fue insistentemente sostenida en el seno de la comisión que elaboró el proyecto de ley de prensa al que antes aludimos.

Consecuente con lo anterior fundamentó esa profesionalidad en el derecho a la adecuada, oportuna y veraz información del que son titulares todos los integrantes de la sociedad. Ese derecho, absolutamente fundamental en un régimen democrático, requiere ser satisfecho para que tal sistema pueda funcionar. La realidad contemporánea nos muestra que esto sólo es posible con el desempeño profesional de quienes sienten la vocación para ello y se 
preparan adecuadamente con el fin de cumplir esa labor de servicio social. Así surge el deber profesional de informar del que son sujetos activos los periodistas.

En esa línea la revista se preocupó de insistir en el contenido de ese deber de informar y de sus exigencias éticas, técnicas y legales. Sobre todo se exaltó la fundamental actitud de veracidad dentro de la cual, cualquiera sea su inclinación ideológica, debe moverse el periodista. Como contrapartida de aquel deber, ejercido en conformidad con los parámetros señalados, surge el derecho preferente a informar, acceder a las fuentes de información, acogerse al secreto profesional, estar exento de censura previa y de indebidas presiones 0 prohibiciones, todas atribuciones inherentes a la función profesional de periodista, que las Cartas o Códigos de Etica profesional o las disposiciones legales reconocen o deben reconocer.

Esta posición permanente de la revista fue ratificada por el Rector de la Universidad quien en el discurso que pronunció en el acto de celebración de los cuarenta años de la Escuela de Periodismo finalizó diciendo:

"Yo pienso que nuestra Escuela de Periodismo que cumple sus cuarenta años de instalación, tiene derecho a mirar no sólo el pasado que fue sino el futuro que viene y que será cada vez más exigente con la calidad informativa y con la ética que entrega a quienes se forman en esta Universidad y sobre todo en esta Escuela".

\section{Augurio}

El Periodismo es una hermosa profesión. Hoy puede usar medios tecnológicos que hace 47 años todo lo más eran patrimonio de la ciencia ficción. La comunicación de las noticias es instantánea; la cantidad de informaciones disponibles es abrumadora. En este mar sin límites el periodismo intenta cada 24 horas conformar un cuadro de lo que durante ellas ocurrió. Lo que se considera más importante y más interesante y más atractivo y más estimulante y más lucrativo y más...

El periodismo es una peligrosa profesión. Hay que seleccionar, escoger, ordenar, desechar. Todo esto no en un limbo tranquilo y transparente sino en un entorno social, político, ideológico, financiero, empresarial donde los intereses se entrecruzan y se provocan muchas colisiones, en un ambiente mezcla de nobleza y sordidez, de rectitudes y de vicios, donde se pone a prueba la resistencia o la entrega, las grandezas y las caídas de cada periodista.

El periodismo es una difícil profesión. Raramente produce riquezas materiales. Supone mucha entrega y dedicación a labores no siempre atractivas. Recibe más denuestos que alabanzas. Muy pocos periodistas son estrellas. La gran mayoría se desempeña en el anonimato.

El periodismo es una noble profesión. Requiere adiestramiento técnico, exige verdadera vocación, necesita sobre todo una profunda y vital formación ética.

La Escuela de Periodismo pretende acercar a sus alumnos a la vivencia de esos valores, el primero de los cuales es la veracidad, recordando aunque no se mencione a su autor, la frase imperecedera: la verdad os hará libres.

"Comunicación y Medios" en su primera etapa pretendió servir esos ideales. Estamos ciertos que en su edición 2000 cumplirá con creces tales objetivos. 